\title{
THE RELIABILITY AND USEFULNESS OF THE SUWA NOMOGRAM IN PATIENTS IN RESPIRATORY FAILURE
}

\author{
WILliaM W. STOYKA, B.SC., M.D."
}

IN 1954, Radford predicted ventilation standards for prolonged artificial ventilation which would determine tidal volumes for any respiratory frequency. ${ }^{1{ }^{2}}$ The ventilation standards were intended as a guide for the maintenance of carbon dioxide removal and made no assumptions regarding adequate oxygenation.

Pontoppidon et al. ${ }^{3}$ demonstrated the need for increased ventilation and oxygen requirements in patients with respiratory failure. During intermittent positive pressure ventilation, inequalities of ventilation-perfusion occurred as shown by increases in physiological dead space and venous admixture effect. It was proposed that this venous admixture effect, manifested as an alveolar-arterial oxygen difference $\left(\mathrm{A}-\mathrm{a} \Delta \mathrm{O}_{2}\right)$, resulted from perfusion of areas of miliary atelectasis. ${ }^{4}$ To prevent atelectasis and maintain adequate oxygenation, Pontoppidon, Laver, ${ }^{5}$ and Hedly-Whyte ${ }^{\theta}$ advocated the use of constant tidal ventilation at twice the ventilation standards predicted by Radford.

The common result of using tidal volumes twice the ventilation standards is the production of hypocapnea. The possible harmful effects of hypocapnea may include compensatory metabolic acidosis mediated through the kidney, ${ }^{7,8}$ impaired tissue perfusion and oxygenation due to a shift of the oxyhaemoglobin dissociation curve, ${ }^{9,10}$ possible decreased cerebral blood flow and cerebral hypoxia, ${ }^{11-14}$ resetting of the central chemoreceptors controlling central respiratory effort, ${ }^{15,16}$ possible decrease in cardiac output and stroke volume, ${ }^{17-19}$ and tetany. ${ }^{20,21}$

The effects of hypocapnea have led investigators to propose solutions to this problem. Three methods are available to prevent hypocapnea and maintain large tidal volumes during prolonged artificial ventilation. The simplest method is to reduce the frequency of ventilation. The second method is the addition of carbon dioxide to the inspired air. The third method is the addition of mechanical dead space to the breathing circuit. In 1968, Suwa and Bendixen devised a mathematical equation to facilitate the addition of mechanical dead space. ${ }^{22}$ In this equation the arterial carbon dioxide tension was predicted for any volume addition of mechanical dead space, and from it Suwa devised a nomogram to facilitate the determination of the mechanical dead space which would produce a normal arterial carbon dioxide tension of $40 \mathrm{~mm} \mathrm{Hg.}{ }^{23,24}$

The purpose of this study is to investigate the reliability and usefulness of the Suma nomogram and the mathematical equation on which the nomogram is based. The mathematical equation was used in the clinical study of nine patients in respiratory failure. The ability of the nomogram to predict the mechanical dead space necessary to produce a normal arterial carbon dioxide tension of $40 \mathrm{~mm} \mathrm{Hg}$ was compared with the achieved values derived from the clinical study.

'Department of Anaesthesia, University of Toronto. 


\section{Mathematical Analysis and Use of the Suwa Nomogram}

The basis of the Suwa nomogram is an equation which predicts the arterial carbon dioxide tension for any volume addition of mechanical dead space.

$$
\begin{aligned}
\mathrm{Pa}_{2} \mathrm{CO}_{2} & =\mathrm{Pa}_{1} \mathrm{CO}_{2}+\left(\mathrm{P}_{A_{1} \mathrm{CO}_{2}} \times \frac{\mathrm{VD}_{\mathrm{M}}}{\mathrm{VT}-\mathrm{VDan}-\mathrm{VD}_{\mathrm{M}}}\right) \\
\mathrm{Pa}_{2} \mathrm{CO}_{2} & =\text { achieved } \mathrm{Pa}_{\mathrm{CO}_{2}} \\
\mathrm{~Pa}_{1} \mathrm{CO}_{2} & =\text { initial } \mathrm{Pa}_{\mathrm{CO}_{2}} \\
\mathrm{PA}_{1} \mathrm{CO}_{2} & =\text { alveolar component of expired gas } \mathrm{CO}_{2} \\
\mathrm{VD}_{\mathrm{M}} & =\text { volume of mechanical dead space } \\
\mathrm{VT} & =\text { tidal volume } \\
\mathrm{VDan} & =\text { anatomical dead space volume. }
\end{aligned}
$$

It can be seen that equation 1 can be solved for mechanical dead space. Substituting any desired value for achieved arterial carbon dioxide tension will enable the determination of the mechanical dead space necessary to produce the desired value as shown by equation 2 .

$$
\mathrm{VD}_{\mathrm{M}}=\frac{\mathrm{Pa}_{2} \mathrm{CO}_{2}-\mathrm{Pa}_{1} \mathrm{CO}_{2}}{\mathrm{~Pa}_{2} \mathrm{CO}_{2}-\left(\mathrm{Pa}_{1} \mathrm{CO}_{2}-\mathrm{PA}_{1} \mathrm{CO}_{2}\right)} \times(\mathrm{VT}-\mathrm{VDan})
$$

The value for carbon dioxide tension of the alveolar component remains to be solved. Expired gas contains dead space volume and alveolar gas volume, with each component having its own carbon dioxide tension. The carbon dioxide tension of the alveolar component was derived by substitution into the Bohr equation. The result of this substitution is equation 3 .

$$
\mathrm{PA}_{1} \mathrm{CO}_{2}=\frac{\mathrm{PE}_{\mathrm{CO}_{2}} \times \mathrm{VT}}{\mathrm{VT}-\mathrm{VDan}}
$$

where $\mathrm{PE}_{\mathrm{CO}_{2}}=$ mixed expired $\mathrm{CO}_{2}$.

The carbon dioxide tension of mixed expired gas is easily measured. To simplify the measurements and calculations of equations 1 and 2, Suwa devised a nomogram to predict the mechanical dead space required to produce a normal arterial carbon dioxide tension of $40 \mathrm{~mm} \mathrm{Hg}$.

Using equation 2, Suwa derived two equations from which his nomogram was devised. ${ }^{24}$ In the case of patients with normal ventilation perfusion relationships, equation 4 was used:

$$
\mathrm{VDM}=\frac{40-\mathrm{Pa}_{1} \mathrm{CO}_{2}}{35} \times(\mathrm{VT}-\mathrm{VDan})
$$

where 40 is the desired $\mathrm{Pa}_{\mathrm{CO}}$ and 35 is the value for $\mathrm{Pa}_{1} \mathrm{CO}_{2}-\mathrm{PA}_{1} \mathrm{CO}_{2}$. 


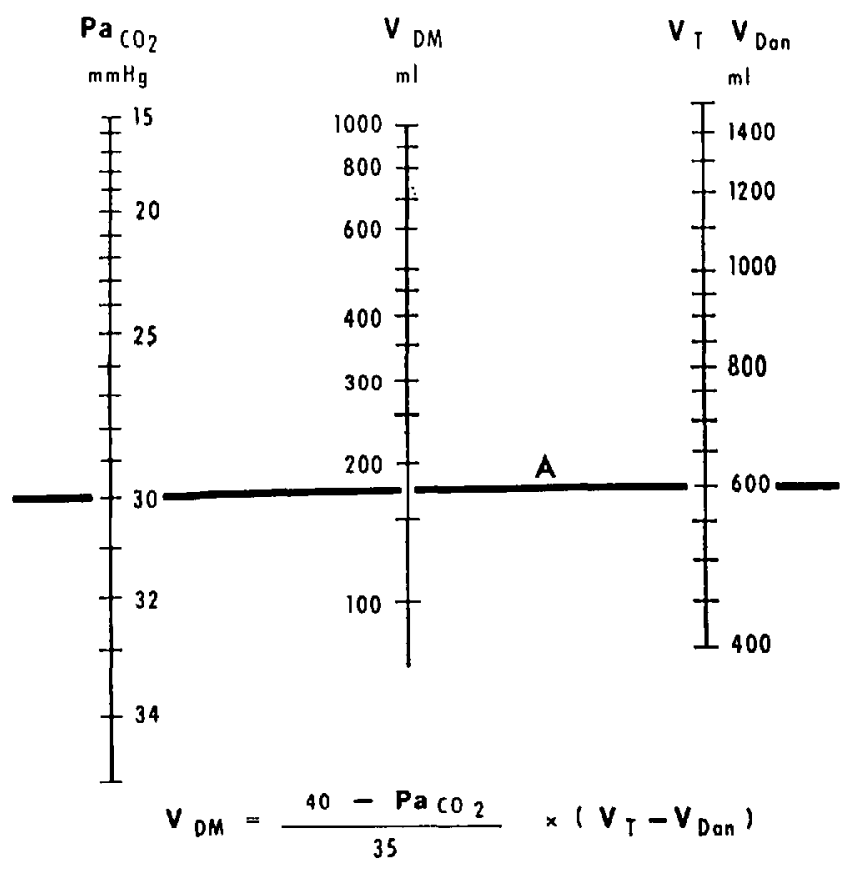

(Equation No.4)

Figure 1. An example for calculating the volume of mechanical dead space (VDM) required for a patient with normal ventilation-perfusion ratios $(\dot{V} / \dot{Q})$ is shown by line $A$.

Figure 1 presents an example for the determination of mechanical dead space by the Suwa nomogram where normal ventilation-perfusion ratios occur.

In the case of patients with abnormal ventilation perfusion ratios, equation 5 was used:

$$
\mathrm{VDM}=\frac{40-\mathrm{Pa}_{1} \mathrm{CO}_{2}}{40-\left(\mathrm{Pa}_{1} \mathrm{CO}_{2}-\mathrm{PE}_{\mathrm{CO}_{2}}\right)} \times(\mathrm{VT}-\mathrm{VDan})
$$

In patients on ventilators with normal ventilation-perfusion ratios the normal arterial-alveolar carbon dioxide difference is less than $5 \mathrm{~mm} \mathrm{Hg}$ (equation 4). In patients with abnormal ventilation-perfusion ratios the arterial-alveolar carbon dioxide difference is greater than $5 \mathrm{~mm} \mathrm{Hg}$. Wasted ventilation with increased dead space produces alveolar air which contains less carbon dioxide than in normal patients. When these patients rebreathe alveolar gas, they are breathing gas with a lower carbon dioxide tension, which will be above, but close to, the carbon dioxide tension of normal air. Rebreathing this gas will produce little effect on arterial carbon dioxide tension. The obvious conclusion is that the amount of mechanical dead space must be raised above that predicted for patients with normal ventilation-perfusion ratios if the carbon dioxide tension is to approximate $40 \mathrm{~mm} \mathrm{Hg}$. 


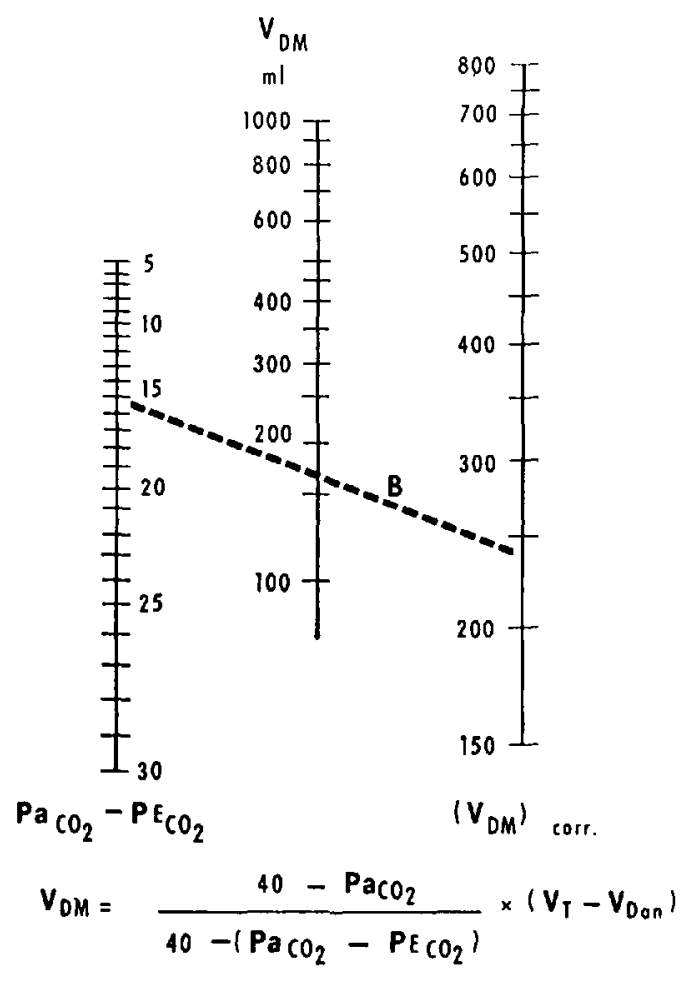

(Equation No.5)

Figure 2. An example for calculating the VDM required for a patient with abnormal $V / Q$ ratios is shown as line $B$. This requires a measured $\mathrm{PECO}_{2}$ and derivation of $\mathrm{VDM}_{\mathrm{DM}}$ from equation 5 to obtain a corrected VDM.

Figure 2 illustrates a sample calculation for mechanical dead space in patients with abnormal ventilation-perfusion ratios. After the measurement of the carbon dioxide tension of expired gas and after derivation of the mechanical dead space as described in Figure 1, a corrected value for mechanical dead space is obtained which is larger than the value obtained in a normal patient.

Figure 3 represents the Suwa nomogram with calculation $A$ for normal ventilation perfusion ratios and calculations $\mathrm{A}$ and $\mathrm{B}$ for patients with abnormal ventilation-perfusion ratios.

\section{Methods}

Nine patients were studied on constant volume, time cycled ventilators (Engstrom). Tidal volumes were twice the predicted ventilation standards. Ventilation was kept at this level for approximately 24 hours. Adequate oxygenation was maintained with all arterial oxygen tensions about $100 \mathrm{~mm} \mathrm{Hg}$. Circulatory stability was maintained for 24 hours as evidence by stable blood pressure, pulse, and central venous pressure.

Expired gas was collected in a 200 L Douglas bag over five minutes' time. The 


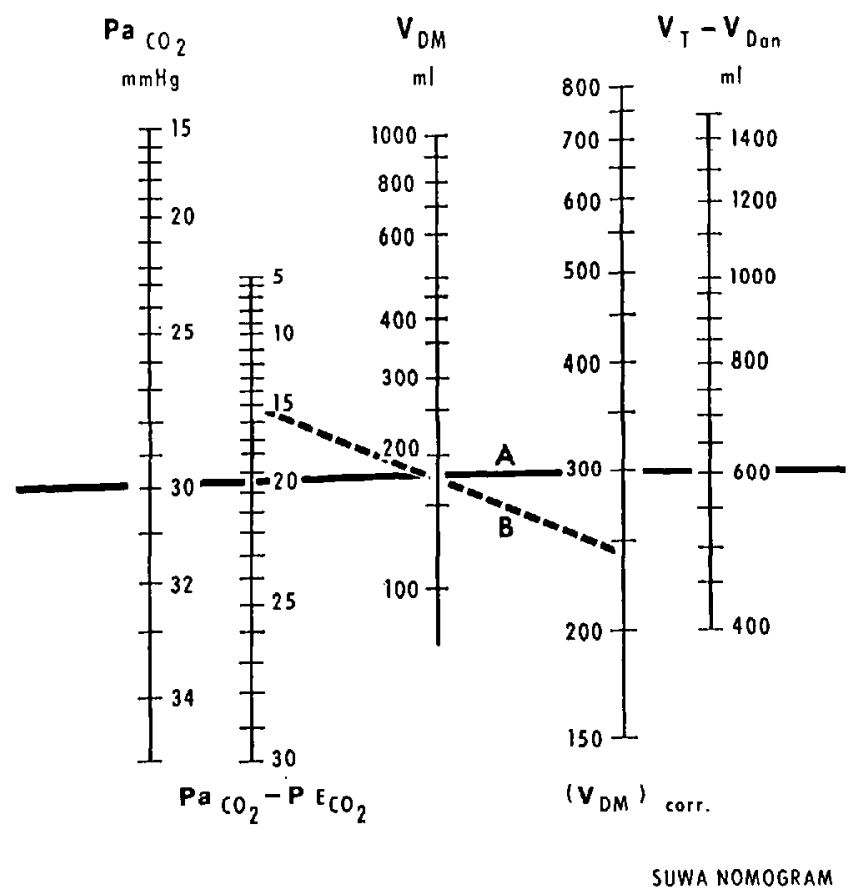

Figure 3. The Suwa nomogram with the sample calculations $A$ and $B$ from Figures 1 and 2 . With normal $V / Q$ ratios calculation $A$ is sufficient. With abnormal $V / Q$ ratios calculations $A$ and $B$ must be done.

concentration of carbon dioxide in the expired air was measured by an infrared analyser (LB1). The total volume of expired gas was measured in a calibrated dry gas meter which permitted the measurement of tidal volumes. To insure no mixing of inspiratory and expiratory gas, and to remove the possibility of compressible volumes, an efficient non-return valve was inserted into the breathing system.

A long stay plastic catheter was inserted into the femoral artery for arterial blood sampling. Arterial blood was taken from the arterial line in a heparinized syringe and analysed for arterial oxygen tension, arterial carbon dioxide tension, and $\mathrm{pH}$. This analysis was done at $37^{\circ} \mathrm{C}$ on a $\mathrm{pH} /$ gas analyser (Instrumentation Laboratories 113-s 1) within five minutes of taking the arterial blood.

The volume of anatomical dead space was determined using $2 / 3$ of the body weight in pounds, plus the dead space in the tracheostomy tube and the tubing to the Y-connector of the Engstrom. The results of the four measurements for tidal volume, anatomical dead space, arterial carbon dioxide tension, and the carbon dioxide tension of mixed expired air were used to determine the mechanical dead space predicted by the Suwa nomogram to produce an arterial carbon dioxide tension of $40 \mathrm{~mm} \mathrm{Hg}$. Mechanical dead space was then added in the form of clear plastic tubing with negligible compliance and an internal diameter of $21 \mathrm{~mm}$. The volume of this tubing was determined by volume displacement with water. The volume of mechanical dead space initially was between $1 / 2$ and 


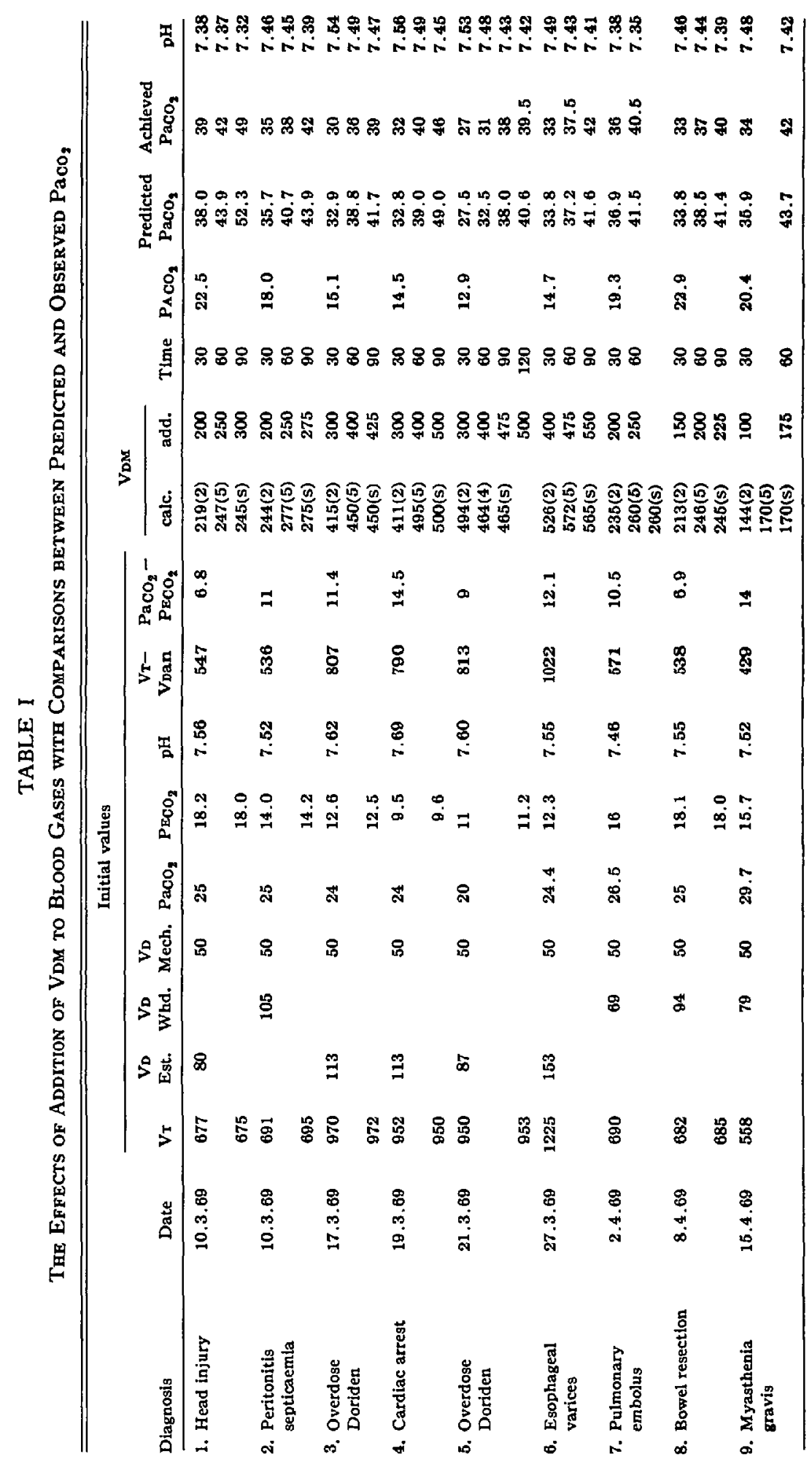


$2 / 3$ of the mechanical dead space calculated to produce a normal arterial carbon dioxide tension. To allow for the achievement of a steady state, the measurements were repeated only after a lapse of 30 minutes. The process was repeated with the addition of either further increments or the total calculated dead space. Samples were withdrawn at half-hour intervals, and measurements were made as described previously.

\section{Results}

Table I represents the parameters studied and the results obtained from nine patients. This data allowed a comparison between the calculated arterial carbon dioxide tension and the observed carbon dioxide tension when mechanical dead space was added. Figure 4 is a graphic illustration of this relationship. On the $\mathrm{X}$-axis is the observed arterial carbon dioxide tension. On the $\mathrm{Y}$-axis is the predicted arterial carbon dioxide tension determined from equation 1 . In 26 samples, the mean difference between the observed and the predicted values was $1.14 \mathrm{~mm} \mathrm{Hg}$. The standard error of $1.23 \mathrm{~mm} \mathrm{Hg}$ found by Suwa was five times as large as the value of $0.26 \mathrm{~mm} \mathrm{Hg}$ found in this study. Equation 1 was found to be valid for predicting arterial carbon dioxide tensions through a range of 30 to $50 \mathrm{~mm} \mathrm{Hg}$. Values obtained in excess of $40 \mathrm{~mm} \mathrm{Hg}$ will be explained shortly.

A comparison was made between the mechanical dead space derived from equation 4 or 5 and the Suwa nomogram which is shown in Table II. The difference between these two methods for deriving mechanical dead space was

TABLE II

COMPaRISON OF VDM DERIVED FROM

EQUATIONS 4 OR 5 AND THE SUWA NOMOGRAM With the Resultant Predicted $\mathrm{PaCO}_{2}$

\begin{tabular}{ccc}
\hline $\begin{array}{c}\text { VDM } \\
\text { (equation 4 } \\
\text { or 5) }\end{array}$ & $\begin{array}{c}\text { VDM (Suwa } \\
\text { nomogram) }\end{array}$ & $\begin{array}{c}\mathrm{Paco}_{2} \\
\text { (equation 1) }\end{array}$ \\
\hline 247 & 250 & 43.5 \\
277 & 275 & 44.2 \\
450 & 450 & 43.0 \\
495 & 500 & 48.3 \\
464 & 465 & 37.2 \\
572 & 565 & 43.1 \\
260 & 260 & 42.6 \\
245 & 245 & 44.1 \\
170 & 170 & 43.1 \\
\hline
\end{tabular}

Mean difference $\overline{\mathrm{x}}=3.23$.

Variance $S^{2}=8.04$

Standard deviation s.d. $=2.84$.

Standard error of mean $\mathrm{S}_{\mathrm{x}}=0.95$.

approximately 1 per cent, which was considered insignificant. The mechanical dead space derived from the nomogram was then substituted into equation 1 to obtain the arterial carbon dioxide tension. This resulted in predicted arterial carbon dioxide tensions larger than $40 \mathrm{~mm} \mathrm{Hg}$ in 8 of the 9 patients. The mean difference from the normal value of $40 \mathrm{~mm} \mathrm{Hg}$ was $\pm 3.23 \mathrm{~mm} \mathrm{Hg}$ for arterial 


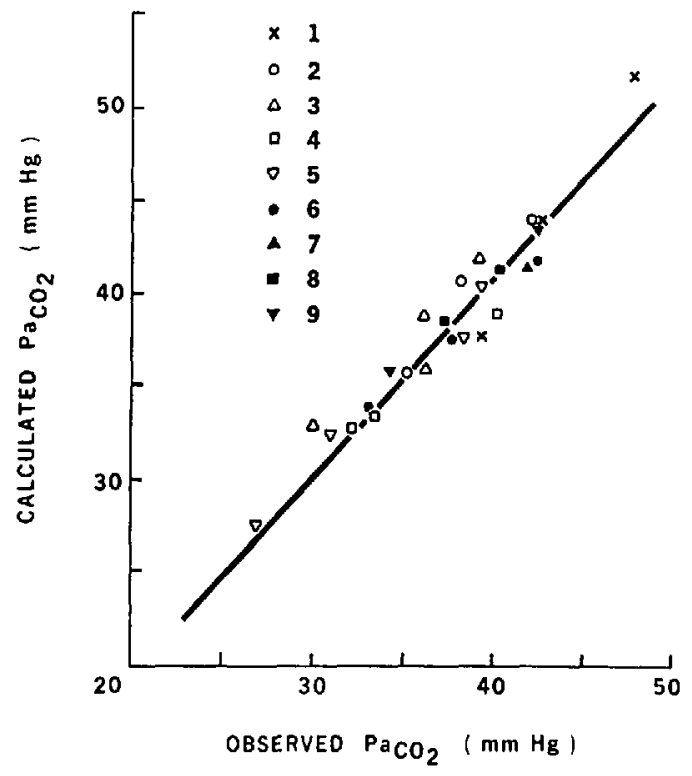

Frgure 4. The relationship between the observed $\mathrm{PaCO}_{2}$ and the calculated $\mathrm{PaCO}_{2}$ derived from equation 1 is shown in nine patients.

carbon dioxide tension. This was less than the potential error of $\pm 5 \mathrm{~mm} \mathrm{Hg}$ predicted by Suwa.

\section{Discussion}

The prediction of arterial carbon dioxide tensions in excess of 40 by the nomogram and equation 1 caused several problems. Elevated carbon dioxide tensions have been shown to produce the sensation of dyspnoea. Spontaneous respiratory effort occurred around the ventilator in Suwa's study. These problems were avoided in five of the nine patients in this study by the prudent use of sedation. Two patients were receiving relaxant therapy and no problems arose. Two of the nine patients could not be studied at $\mathrm{PaCO}_{2}$ values above $40 \mathrm{~mm} \mathrm{Hg}$ since spontaneous respiratory efforts occurred at this level.

The Suwa nomogram is only reliable in predicting the mechanical dead space required to produce a normal arterial carbon dioxide tension if we are willing to accept a possible error of $\pm 5 \mathrm{~mm} \mathrm{Hg}$. In this study, the magnitude of the error was $\pm 3 \mathrm{~mm} \mathrm{Hg}$. The problems arising from the use of the Suwa nomogram occur when the arterial carbon dioxide tension rises above $40 \mathrm{~mm} \mathrm{Hg}$. Dyspnoea and spontaneous respiratory effort occur as described previously with elevated arterial carbon dioxide tensions.

Equation 1 was the mathematical analysis from which the nomogram was derived. Its validity and clinical usefulness were shown in 26 samples. The magnitude of the error using equation 1 was less than $\pm 1 \mathrm{~mm} \mathrm{Hg}$ from the normal value of $40 \mathrm{~mm} \mathrm{Hg}$. An attempt was made to devise a nomogram based on equation 1 . The result was an unwieldy three-stage nomogram, which was abandoned. It was then found that this equation could be easily programmed into 
a small electronic computer (Wang). The addition of mechanical dead space can now be done by this method in our unit.

Equation $I$ and the Suwa nomogram serve an important function. The clinician who treats patients in respiratory failure is now aware of the large volume of mechanical dead space which may be required to produce a normal arterial carbon dioxide tension. This is evidenced by the mechanical dead space used in this study which ranged from 175 to 500 millilitres. Equation 1 is useful for patients in respiratory failure. It can only be used for patients on constant volume, time-cycled ventilators who are receiving large tidal volumes. The accuracy and utility of equation 1 obviates the necessity to use the Suwa nomogram in the laboratory situation; however, when facilities do not allow accurate assessment of equation 1, the Suwa nomogram may be used as a substitute.

\section{SuMMary}

The Suwa nomogram was devised to predict the amount of mechanical dead space which must be added to a ventilated patient's breathing circuit to achieve a normal arterial carbon dioxide tension of $40 \mathrm{~mm} \mathrm{Hg}$ from a hypocapnoeiac level. The reliability of the mathematical analysis from which the nomogram was derived, together with the Suwa nomogram itself, were assessed in nine patients in respiratory failure. The results from 26 samples verified the mathematical analysis with a difference of $\pm 1 \mathrm{~mm} \mathrm{Hg}$ from the predicted value of $40 \mathrm{~mm} \mathrm{Hg}$ for arterial carbon dioxide tension when mechanical dead space was added. The mechanical dead space predicted by the Suwa nomogram to achieve an arterial carbon dioxide tension of $40 \mathrm{~mm} \mathrm{Hg}$ was shown to have a potential error of \pm 3.23 $\mathrm{mm} \mathrm{H}$. It was shown that the mathematical analysis warranted more use than the Suwa nomogram because of superior accuracy.

\section{RÉsUMÉ}

Le nomogramme Suwa a été établi pour prédire le volume d'espace mort mécarique quil faut ajouter au circuit d'un malade ventilé pour obtenir une tension de $\mathrm{CO}_{2}$ artériel normale de $40 \mathrm{~mm} \mathrm{Hg}$ à partir de l'apnée. L'analyse mathématique fiable à partir de laquelle le nomogramme a été établi et le nomogramme Suwa lui-même ont été évalués chez neuf malades en détresse respiratoire. Les résultats de 26 échantillons ont vérifié l'analyse mathématique avec une différence de $\pm 1 \mathrm{~mm} \mathrm{Hg}$ de la valeur prédite de $40 \mathrm{~mm} \mathrm{Hg}$ pour la tension de $\mathrm{CO}_{2}$ artériel lorsque l'espace mort mécanique était ajouté au vol $/ \mathrm{min}$. L'espace mort mécanique prédit par le nomogramme Suwa pour obtenir une tension de $\mathrm{CO}_{2}$ artériel de $40 \mathrm{~mm} \mathrm{Hg}$ peut entrainer une erreur de $\pm 3.23 \mathrm{~mm} \mathrm{Hg}$. On a démontré que l'analyse mathématique s'avère d'une plus grande utilité que le nomogramme Suwa à cause d'une précision supérieure.

\section{ACKNOWLEDGMENTS}

The author wishes to acknowledge the technical assistance of the Medical Art Department, University of Toronto, and Miss Bernice Fredericks and Miss Laureen Dudych in the preparation of this manuscript. 


\section{REFERENCES}

1. Radford, E. P., JR. Ventilation Standards for Use in Artificial Respiration. J. Appl. Physiol. 7: 451 (1955).

2. Radfond, E. P., Jr.; Ferrus, B. J.; \& KruEte, B. C. Clinical Use of Nomogram to Estimate Proper Ventilation during Artificial Respiration. New England J. Med. 251: 877 (1954).

3. Pontoppidon, H.; Hedley-Whyte, J.; Bendixen, H. H.; Laver, M. B.; \& Radford, E. P., JR. Ventilation and Oxygen Requirements during Prolonged Artificial Ventilation in Patients with Respiratory Failure. New England J. Med. 273: 401 (1965).

4. Bendixen, H. H.; Hedley-Whyte, J.; \& Laver, M. B. Impaired Oxygenation in Surgical Patients during General Anaesthesia with Controlled Ventilation: A Concept of Atelectasis. New England J. Med. 269: 991 (1963).

5. Layer, M. B.; Lotstrom, B.; Heitman, H.; \& Pontoppidon, H. Dead Space during Controlled Ventilation. Anesthesiology. 27: 220 (1966).

6. Hedley-Whyte, J.; Pontoppidon, H.; Laver, M. B.; Hallowell, P.; \& Bendixen, H. H. Arterial Oxygenation during Hypothermia. Anesthesiology. 26: 595 (1965).

7. Robinson, J. S. Some Biochemical Effects of Passive Hyperventilation. Brit. J. Anaesth. 33: 69 (1961).

8. PitTs, R. F., ed. Physiology of the Kidney and Body Fluids. Year Book Medical Publishers. 2nd ed. (1968), p. 187.

9. Roughton, F. J. W. Transport of Oxygen and Carbon Dioxide. Handbook of Physiology Respiration. Washington, D.C. Am. Physiol. Soc. (1964), sect. 3, vol. 1, ch. 31, pp. $767-826$.

10. Suskind, M. \& RaHN, H. Relationship between Cardiac Output and Ventilation and Gas Transport, with Particular Reference to Anaesthesia. J. Appl. Physiol. 7: 59 (1954).

11. KefY, S. S. \& Sснмпт, C. F. The effects of Altered Arterial Tensions of Carbon Dioxide and Oxygen on Cerebral Blood Flow and Cerebral Oxygen Consumption of Normal Young Men. J. Clin. Invest. 27: 484 (1948).

12. Cuutron-Brock, J. The Cerebral Effects of Overventilation. Brit. J. Anaesth. 29: 111 (1957).

13. Sugroka, K. \& Davis, D. A. Hyperventilation with Oxygen: Possible Cause of Cerebral Hypoxia. Anesthesiology. 21: 135 (1960).

14. Wollman, H.; Craighead, Alexander S.; Cohen, P. J.; Smith, T. C.; Chase, P. E.; \& Van Der Molen, R. F. Cerebral Circulation during General Anaesthesia and Hyperventilation in Man. Anesthesiology. 26: 329 (1965).

15. Mrtchell, R. A. Cerebrospinal Fluid and the Regulation of Respiration. In Care, C., ed. Advances in Respiratory Physiology. London: Arnold (1966).

16. Kazemi, H.; Shannom, D. C.; \& Carvallo-Gil, E. Brain $\mathrm{CO}_{2}$ Buffering Capacity in Respiratory Acidosis and Alkalosis. J. Appl. Physiol. 22: 241 (1967).

17. Prys-Roberts, C.; Kelman, C. R,; Greenbaum, R.; \& Robinson, R. H. Circulatory Influences of Artificial Ventilation during Nitrous Oxide Anaesthesia in Man: II. Results: The Relative Influence of Mean Intrathoracic Pressure and Arterial Carbon Dioxide Tension. Brit. J. Anaesth. 39: 533 (1967).

18. Morgan, B. C.; Crawford, E. W.; Hornbein, T. F.; Martin, W. E.; \& Guntheroth, W. G. Hermodynamic Effects of Changes in Arterial Carbon Dioxide Tension during Intermittent Positive Pressure Ventilation. Anesthesiology. 28: 866 (1967).

19. Counmand, A.; Motrey, H. L.; Werko, C.; \& Richards, D. W., Jr. Physiological Studies of the Effects of Intermittent Positive Pressure Breathing on Cardiac Output in Man. Am. J. Physiol. 152: 162 (1948).

20. Fanconnt, A. \& Rose, G. A. The Ionised, Complexed and Protein Bound Fractions of Calcium in Plasma. Quart. J. Med. 27: 463 (1958).

21. Hodgkin, A. L. Ionic Movements and Electrical Activity in Giant Nerve Fibers. Proc. Roy. Soc. B, 148: 1 (1958).

22. Suwa, K. \& BENDixen, H. H. A Mathematical Analysis of Physiological Dead Space in a Lung Model. J. Appl. Physiol. 24: 549 (1968).

23. Suwa, K. \& Bendixen, H. H. Change in $\mathrm{PaCO}_{2}$ with Mechanical Dead Space during Artificial Ventilation. J. Appl. Physiol. 24: 556 (1968).

24. Suwa, K.; Geffin, B.; Pontoppidon, H.; \& Bendixen, H. H. A. Nomogram for Dead Space Requirement during Prolonged Artificial Ventilation. Anesthesiology, 29: 1206 (1968). 